\title{
Relationship between attention and balance: a dual-task condition study in children
}

\author{
Vanesa Abuin-Porras' ${ }^{1}$, Jorge Hugo Villafañe ${ }^{2 * *}$, Carmen Jiménez-Antona ${ }^{3}$, Antonio Palacios ${ }^{4}$, Beatriz Martínez-Pascual ${ }^{5}$, \\ Isabel Rodríguez-Costa ${ }^{6}$
}

${ }^{1}$ Grupo de investigación en dolor musculoesquelético y control motor UE, Universidad Europea de Madrid, Madrid, Spain

${ }^{2}$ IRCCS Fondazione Don Carlo Gnocchi, Milan, Italy

${ }^{3}$ Universidad Rey Juan Carlos, Madrid, Spain

4Universidad Autónoma de Madrid, Madrid, Spain

5Universidad Europea de Madrid, Madrid, Spain

${ }^{6}$ Universidad de Alcalá de Henares, Alcalá de Henares, Spain

This study explored the relationship between motor functions and attention in children aged $4-5$ years. A sample of 85 children was collected from a primary school (44 boys and 41 girls). We applied a standardized continuous attention performance test, the Kiddie Continuous Performance Test, under two conditions (sitting and balancing). Data were collected from two standardized balance tests, the Battelle and Pediatric Balance Scale. There was a significant relationship between atten- tion and balance and gender differences that may condition the way to address balance issues in boys and girls. Gender should be considered when addressing balance problems to get efficient interventions. Balance skill may be a contributing factor in attention-deficit/hyperactivity disorder.

Keywords: Attention, Balance, Child

\section{INTRODUCTION}

Young children may experience difficulties in sustaining attention while they are being taught. Many factors contribute to attentional performance in the academic context when children are performing concurrent motor and cognitive tasks (Reilly et al., 2008).

In terms of information processing, have summarizes four main functions of attention: signal detection and vigilance, search, selective attention, and divided attention, which is the object of this study. Theories of attention generally agree that attentional resources are limited. In divided attention, available attentional resources are allocated to coordinate the performance of more than one task at a time or the processing of more than one source of information at the same time (McCulloch et al., 2010). The resource models conceive of attention as an energy or fuel, essential for pro- cessing, and of limited availability. There is a limited attention capacity available when two tasks are performed at the same time, so they compete for the resources. If there is need for more resources than the available attention capacity, the two tasks will interfere with each other, and one or both of them will suffer in performance speed or quality.

Additionally, from a mathematical perspective, signal-detection theory (SDT) provides a general framework to describe and study decisions that are made in uncertain or ambiguous situations, and has been used as broad framework to describe human performance on attention tasks. More precisely, two SDT parameters ( $d^{\prime}$ and $\beta$ ) have been proven very useful for studying human attention performance as they represent sensitivity (e.g., the ability to discriminate between signal and noise) and response bias (e.g., the tendency to respond affirmatively).

Subjects perform better on simultaneous attention-demanding
${ }^{\star}$ Corresponding author: Jorge Hugo Villafañe

(ii) https://orcid.org/0000-0002-3239-7626

IRCCS Fondazione Don Carlo Gnocchi, Milan, Italy

Tel: +39-3395857563, Fax: +39-0119065495, E-mail: mail@villafane.it

Received: March 7, 2018 / Accepted: April 25, 2018
This is an Open Access article distributed under the terms of the Creative Commons Attribution Non-Commercial License (http://creativecommons.org/licenses/by-nc/4.0/) which permits unrestricted non-commercial use, distribution, and reproduction in any medium, provided the original work is properly cited. 
tasks when such tasks are in different modalities. Some attentional resources may be specific to the modality (e.g., verbal or visual) of the task (Steindl et al., 2006).

Balance is usually considered the skill of maintaining the position of the body relative to stability limits (McCollum and Leen, 1989). It is an emergent property of a complex, multicomponent sensorimotor system, which clinicians often treat as a single set of automatic reactions (Horak, 2006). In the systems model, maintaining balance requires the integration of sensory information, the ability to generate forces to control one's body position, and cognition (attention and motivation). Three sensorial systems are related to balance: the somatosensory, vestibular, and visual (Shumway-Cook and Horak, 1986). Not all systems have the same influence over balance and its maintenance; children are more influenced by the visual system as they have fewer references from the proprioception system located in the joints due to their lack of motor experience. This visual-propiocepcion interaction is not linear through the childhood period. There are critical phases where the system is adjusting. Assaiante and Amblard (1995) stablished that between 4 and 6 years there was a transition phase where the postural response deteriorates. Similar to babies that have to rely in vision for movement, children at this age have more visual-directed balance. Sun and Jensen (1994) reported that children at this age experimented a period of growth that could be the reason for children to have to rely in vision as their bodies information changes too fast to adapt.

The relationship between balance and attention has been considered as part of postural control (Kim et al., 2017). It has been postulated as a relationship between motor and cognitive factors that is required to explain human behavior related to motor skills (Horak, 2006).

Although there has been extensive research conducted on the relationship between cognitive abilities and balance in senior and impaired adults (Woollacott and Shumway-Cook, 2002), the relationship between attention and balance in children has not received as much attention. Some studies have addressed this topic, but they have used very dissimilar approaches and procedures (Hatzitaki et al., 2002; Livesey et al., 2006; Niederer et al., 2011; Piek et al., 1999; Piek et al., 2004; Roebers and Kauer, 2009), and few explored balance and attention in an isolated way. Balance was usually included in a compendium of motor-coordination skills and attention was usually distributed among several executive functions.

There appear to be no significant differences between genders in balance scores (Franjoine et al., 2003), but gender differences have been shown consistently in attentional performance. Indeed, the attention-deficit/hyperactivity disorder (ADHD) risk index is computed differently by gender (Barnard et al., 2015). It is important to deepen our understanding of the factors that compete for attentional resources during children's performance so that teachers can design age-appropriate environments to improve learning (Reilly et al., 2008).

This project focused on the relationship between balance and attention by collecting static-balance measures and measuring attention under two conditions. The study explored the relationship between these two capacities, to determine if there exists interference between visual attention and balance tasks, and to examine if gender is a mediator variable in the relationship between visual attention and balance in children.

\section{MATERIALS AND METHODS}

\section{Participants}

The sample included 85 children ( 44 boys and 41 girls) aged 4-5 years who were attending a school in Madrid, Spain. The participants had not been diagnosed with either ADHD or any other psychological or serious medical conditions (including any balance impairments). Such diagnoses were considered exclusion criteria in. The study was approved by the Institutional Review Board of Universidad Rey Juan Carlos, Madrid, Spain (approval number: 060520165416) and written informed assent was obtained from the participants' legal guardians.

\section{Attention test}

We applied a standardized attention test, the Conners' Kiddie Continuous Performance Test (K-CPT) (Barnard et al., 2015) under two situations: the standard test condition ("sitting condition," SC) and a "balance condition" (BC). The SC used the standard setup for the test, while in the $\mathrm{BC}$ the children responded the test while standing on a balance board. In terms of attention, the primary task was the K-CPT and the secondary task was maintaining balance. These conditions can be considered analogous to "noninterference" and "interference" test conditions as used in divided-attention experiments.

The K-CPT test is a standardized, computerized, continuous performance test. In the test, responders are asked to pay attention to a sequence of pictures appearing on a screen and to press the left mouse bottom for every picture that appears except for those that show a ball. It includes multiple performance measures related to attention: inattention, impulsivity, vigilance, and ADHD 
risk. Considering K-CPT scores, the study focused on five parameters—omissions $(\mathrm{OM})$, commissions $(\mathrm{COM})$, reaction time (RT), d-prime $\left(d^{\prime}\right)$, and beta ( $\beta$ - - given their relevance as fundamental attention measures. The ADHD risk index given by the test was also considered, due to its relevance as a general attention-factor measure.

\section{Balance test}

Balance was assessed using two standardized tests: the balance-related items for 4 and 5 years of age of the Batelle Developmental Inventory (BATTOT) (Rizzoli-Córdoba et al., 2015) and the Pediatric Balance Scale (PBSTOT) (Franjoine et al., 2003).

\section{Study protocol}

The study procedure included two blocks: K-CPT (block A) and PBS and Battelle (block B). Block order was randomized among the participants using a random number table, such that half of the children followed an $\mathrm{AB}$ sequence and the other half followed a BA sequence.

The K-CPT test was applied under two conditions. In the first condition, the standard seated condition, each child responded to the K-CPT test while seated on a regular chair, which was adjusted to his or her height so that his or her feet were on the floor with the computer on a table in front. In the second condition, the child performed the test while standing on a balance board. This condition was applied in two different ways: the 4-year-old children performed the test while standing on a less unstable board, and the 5-year-old children performed the test on a more unstable board. The objective was to challenge the children's balance, so we created situations of similar difficulty for the two age groups. At this particular stage of development, great differences can be found in balance performance by age (Steindl et al., 2006).

The K-CPT test sessions were randomized within block A: half of the children performed the test first on a stable surface and second on an unbalanced surface, and half of the children in the reverse order. There was a 2-day interval between the two measures to avoid bias due to training. In block B, the Battelle and PBS tests were applied in randomized order, following standardized procedures.

\section{Statistical analysis}

Data were analysed using IBM SPSS Statistics ver. 22.0 (IBM Co., Armonk, NY, USA). The data were normally distributed, as demonstrated by the Kolmogorov-Smirnov test. Significance was set at $P<0.05$, with Bonferroni correction. Attention performance in SC and $\mathrm{BC}$ conditions was compared via t-tests. To analyze relationships between variables we used the Spearman correlation coefficient, and to compare gender outcomes, we conducted Student $t$-test.

\section{RESULTS}

\section{Relationship between balance and attention}

The correlations between K-CPT scores and balance tests appear in Table 1. For the SC test, there were several small but statistically significant correlations, particularly when considering $\mathrm{OM}, \mathrm{RT}$ s, and $\mathrm{ADHD}$ risk. In the case of $\mathrm{BC}$, an increase in the correlation values compared to the SD condition can be seenmost of which were significant-for OM, COM, RTs, $d^{\prime}$, and ADHD risk

Table 1 shows that the relationships between balance ability and attention in the SC test performance are positive (i.e., the correlations between balance scores and OM, COM, RT, and ADHD risk are significant and negative; conversely, the correlations between balance and $d^{\prime}$ are positive). Therefore, we conclude that there is a small but significant relationship between attention and balance abilities. The $\mathrm{BC}$ test performance shows that this relationship becomes stronger when the attention system is stressed by adding a balance task. Greater balance skills are associated with improved attention performance in terms of reducing OM, COM, and RT - all of which are associated with a decreased ADHD-risk score. Additionally, better balance skills correlate with better stimulus discrimination.

To test the relationship between attention and balance in these experimental conditions, a multiple regression analysis (stepwise method) was performed using the ADHD score in the BC as the dependent variable and PBSTOT scores, BATTOT scores, and $\mathrm{ADHD}$ scores in the $\mathrm{SC}$ as predictor variables.

Table 1. Correlations between balance scores and attention

\begin{tabular}{llllll}
\hline \multirow{2}{*}{ Variable } & \multicolumn{2}{c}{ Sitting condition } & & \multicolumn{2}{c}{ Balance condition } \\
\cline { 2 - 3 } \cline { 5 - 6 } & PBSTOT & BATTOT & & PBSTOT & BATTOT \\
\hline Omissions & $-0.29^{* *}$ & $-0.27^{*}$ & & $-0.25^{*}$ & $-0.31^{* *}$ \\
Commissions & -0.09 & $-0.27^{*}$ & & $-0.27^{*}$ & $-0.26^{*}$ \\
Reaction time & $-0.29^{* *}$ & $-0.23^{*}$ & & $-0.25^{*}$ & $-0.34^{* *}$ \\
$d^{\prime}$ & 0.12 & $0.23^{*}$ & & $0.34^{* *}$ & $0.27^{*}$ \\
$\beta$ & -0.18 & -0.03 & & -0.07 & 0.08 \\
ADHD & $-0.26^{*}$ & $-0.33^{* *}$ & & $-0.32^{* *}$ & $-0.38^{* *}$ \\
\hline
\end{tabular}

PBSTOT, Pediatric Balance Scale; BATTOT, Battelle Developmental Inventory; d', d-prime; ADHD, attention deficit/hyperactivity disorder diagnostic.

${ }^{*} P<0.01 .{ }^{* *} P<0.001$ 
Table 2. Paired attention variables compared between sitting and balancing conditions

\begin{tabular}{|c|c|c|c|c|c|c|c|}
\hline Variable & Mean \pm SD & SEM & $95 \% \mathrm{Cl}$ & $t$ & No. & $P$-value & $d^{\prime}$ \\
\hline OM.SC - OM.BC & $-10.35 \pm 16.21$ & 1.76 & -13.85 to -6.86 & -5.89 & 84 & $<0.001$ & 1.29 \\
\hline COM.SC - COM.BC & $1.66 \pm 9.04$ & 0.98 & -0.29 to 3.61 & 1.69 & 84 & 0.095 & 0.37 \\
\hline RT.SC - RT.BC & $-36.25 \pm 90.92$ & 9.86 & -55.86 to -16.63 & -3.68 & 84 & $<0.001$ & 0.80 \\
\hline$d^{\prime} . S C-d^{\prime} B C$ & $-0.04 \pm 0.42$ & 0.05 & -0.13 to 0.05 & -0.92 & 84 & 0.358 & 0.20 \\
\hline$\beta . S C-\beta . B C$ & $-0.48 \pm 270.89$ & 0.30 & -1.06 to 0.10 & -1.63 & 84 & 0.106 & 0.36 \\
\hline ADHD.SC - ADHD.BC & $-6.36 \pm 17.79$ & 1.93 & -10.19 to -2.52 & -3.30 & 84 & $<0.001$ & 0.72 \\
\hline
\end{tabular}

SD, standard deviation; SEM, standard error of the mean; Cl, confidence interval; d', d-prime; OM, omissions; COM, commissions; RT, reaction time; ADHD, attention deficit/ hyperactivity disorder diagnostic; SC, sitting condition; $\mathrm{BC}$, balancing condition.

There was a significant relationship between ADHD scores in $\mathrm{SC}$ and $\mathrm{BC}(t=5.42, P<0.001)$. However, the balance test scores, especially BATTOT, also significantly contributed to predicting ADHD scores in BC. It should be noted that the relationship between the two ADHD scores is positive, but the relationship between ADHD scores in NC and balance scores is negative, as expected. That is, better performance in BATTOT is associated with decreased ADHD-risk scores.

\section{Effect of balance on attention}

Table 2 shows the results of the $t$-tests comparing attention performance in SC and BC. Balancing influenced attention performance as reflected in $P$-value and $d^{\prime}$ values: Three of six factors changed significantly between conditions (i.e., OM, RTs, and ADHD risk). All reflected poorer performance during balancing ( $>\mathrm{OM},>\mathrm{RT}$, and $>$ ADHD risk). In contrast, other factors remained unaffected by the $\mathrm{BC}$ condition as reflected in their associated $d^{\prime}$ and $\beta$ values.

Previously, we considered the effect of balance on attention in terms of differences in mean performance. We now consider linear effects, i.e., correlations. Results were relatively consistent in BC and SC: correlations were mostly positive and statistically significant $(P<0.001)$. However, the correlation related to response bias $(\beta)$ is the exception, being small and nonsignificant $(r=0.07$, $P>0.05)$.

In general, relationships between balance and attentional performance occurred for accuracy/speed attentional parameters (i.e., $\mathrm{OM}, \mathrm{COM}$, and RT) rather than sensitivity/bias $\left(d^{\prime}, \beta\right)$.

\section{Gender differences in balance and attention}

Table 3 compares PBS and Battelle scores by gender. There were no significant differences between genders regarding balance skills.

Table 4 shows K-CPT scores in SC and BC by gender. There
Table 3. Gender comparison of balance scores

\begin{tabular}{ccccccc}
\hline Variable & No. & Mean \pm SD & SE & $95 \% \mathrm{Cl}$ & $F$ & $P$-value \\
\hline $\begin{array}{c}\text { PBSTOT } \\
\text { Boys }\end{array}$ & 44 & $12.41 \pm 3.34$ & 0.50 & $11.34-13.42$ & & \\
Girls & 41 & $12.41 \pm 3.37$ & 0.52 & $11.35-13.48$ & & \\
BATTOT & & & & & 1.245 & 0.268 \\
Boys & 44 & $6.30 \pm 3.89$ & 0.59 & $5.11-7.48$ & & \\
Girls & 41 & $7.34 \pm 4.74$ & 0.74 & $5.85-8.83$ & & \\
\hline
\end{tabular}

SD, standard deviation; SE, standard error; Cl, confidence interval; PBSTOT, Pediatric Balance Scale; BATTOT, Battelle Developmental Inventory.

were differences between girls and boys for SC. Boys made more commission errors, had faster RTs, smaller $d$ 's, marginally higher $\beta s$, and greater risk of ADHD.

Results in the $\mathrm{BC}$ varied widely; the only significant difference, albeit with a small effect size, was for RT. Boys answered more quickly than girls. This fact becomes more relevant when we recall that there were no gender differences in balance skills; that is, the differences are entirely due to issues related to gender differences in the processing of attentional resources.

Considering all of these results, we conclude that there were gender differences in attention performance in both conditions. Girls performed better than boys for the SC; however, in the BC boys improved their performance while girls' performance worsened.

\section{DISCUSSION}

The aim of this study was to provide further evidence of the psychomotor nature of development, and how motor components, such as balance, and cognitive aspects, such as attention, cannot be considered separately in children (Roebers et al., 2014; van der Fels et al., 2015), nor treated separately in clinical environments. In this study, we found a significant relationship between balance 
Table 4. Gender comparison of Kiddie Continuous Performance Test scores in sitting and balancing conditions

\begin{tabular}{|c|c|c|c|c|c|c|c|}
\hline Variable & Sex & No. & Mean $\pm S D$ & SE & $95 \% \mathrm{Cl}$ & $F$ & $P$-value \\
\hline \multirow[t]{2}{*}{ OM.SC } & Boys & 44 & $20.16 \pm 17.09$ & 2.57 & $14.96-25.35$ & 1.04 & 0.311 \\
\hline & Girls & 41 & $24.12 \pm 18.73$ & 2.92 & $18.21-30.03$ & & \\
\hline \multirow[t]{2}{*}{ OM.BC } & Boys & 44 & $29.7 \pm 22.59$ & 3.41 & $22.84-36.57$ & 1.21 & 0.274 \\
\hline & Girls & 41 & $35.34 \pm 24.65$ & 3.85 & $27.56-43.12$ & & \\
\hline \multirow[t]{2}{*}{ COM.SC } & Boys & 44 & $22.14 \pm 8.68$ & 1.31 & $19.5-24.78$ & 7.45 & 0.008 \\
\hline & Girls & 41 & $16.71 \pm 9.66$ & 1.51 & 13.66-19.76 & & \\
\hline \multirow[t]{2}{*}{ СОМ.BC } & Boys & 44 & $19.11 \pm 9.2$ & 1.39 & $16.32-21.91$ & 1.71 & 0.194 \\
\hline & Girls & 41 & $16.51 \pm 9.11$ & 1.42 & 13.64-19.39 & & \\
\hline \multirow[t]{2}{*}{ RT.SC } & Boys & 44 & $669.71 \pm 111.91$ & 16.87 & 635.68-703.73 & 7.73 & 0.007 \\
\hline & Girls & 41 & $742.92 \pm 130.72$ & 20.42 & 701.66-784.18 & & \\
\hline \multirow[t]{2}{*}{ RT.BC } & Boys & 44 & $706.92 \pm 110.77$ & 16.67 & 673.25-740.6 & 8.83 & 0.004 \\
\hline & Girls & 41 & $778.12 \pm 109.96$ & 17.17 & $743.41-812.83$ & & \\
\hline \multirow[t]{2}{*}{$d^{\prime}$ SC } & Boys & 44 & $0.48 \pm 0.34$ & 0.05 & $0.38-0.58$ & 10.93 & 0.001 \\
\hline & Girls & 41 & $0.76 \pm 0.44$ & 0.07 & $0.62-0.9$ & & \\
\hline \multirow[t]{2}{*}{$d^{\prime} \mathrm{BC}$} & Boys & 44 & $0.62 \pm 0.34$ & 0.06 & $0.5-0.74$ & 0.62 & 0.434 \\
\hline & Girls & 41 & $0.70 \pm 0.49$ & 0.08 & $0.54-0.85$ & & \\
\hline \multirow[t]{2}{*}{ B.SC } & Boys & 44 & $1.81 \pm 1.34$ & 0.20 & $1.41-2.22$ & 2.86 & 0.095 \\
\hline & Girls & 41 & $2.49 \pm 2.26$ & 0.35 & $1.78-3.2$ & & \\
\hline \multirow[t]{2}{*}{$\beta . B C$} & Boys & 44 & $2.60 \pm 1.95$ & 0.294 & $2.00-3.19$ & 0.01 & 0.920 \\
\hline & Girls & 41 & $2.64 \pm 2.29$ & 0.358 & $1.92-3.37$ & & \\
\hline \multirow[t]{2}{*}{ ADHD.SC } & Boys & 44 & $44.34 \pm 14.17$ & 2.14 & $40.03-48.65$ & 8.18 & 0.005 \\
\hline & Girls & 41 & $33.63 \pm 20.04$ & 3.13 & 27.31-39.96 & & \\
\hline \multirow[t]{2}{*}{ ADHD.BC } & Boys & 44 & $45.65 \pm 17.66$ & 2.66 & $40.28-51.01$ & $<0.01$ & 0.958 \\
\hline & Girls & 41 & $45.41 \pm 23.09$ & 3.61 & $38.13-52.7$ & & \\
\hline
\end{tabular}

$\mathrm{SD}$, standard deviation; $\mathrm{SE}$, standard error; Cl, confidence interval; OM, omissions; COM, commissions; RT, reaction time; ADHD, attention deficit/hyperactivity disorder diagnostic; SC, sitting condition; BC, balancing condition; $d^{\prime}$, d-prime.

and visual attention in children. These results were expected given previous outcomes (Hatzitaki et al., 2002; Piek et al., 1999; Piek et al., 2004; Roebers and Kauer, 2009). Nevertheless, prior studies used a variety of sample types (e.g., adult clinical samples) and many variations in variables assessed; as such, the relationship between balance and visual attention cannot be considered fully established. It is necessary to replicate these studies using consistent assessment tools. Note that, studies that used a similar methodology and focused on assessing balance and attention (i.e., using tests specifically of balance and attention) showed similar results.

Woollacott and Shumway-Cook (2002), in their review of the extant research on postural control and attention, reported several studies in adults that showed a strong connection between balance and visual processing (Kerr et al., 1985; Maylor and Wing, 1996), attention (Lajoie et al., 1993; McIlroy et al., 1999), and other cognitive processes (Brown et al., 1999; Stelmach et al., 1990). This study supports these findings, suggesting a visual processing link between balance and attention tasks that causes interference when they are performed at the same time in children aged 4-5.

In one of the few studies including children, Hatzitaki et al. (2002) explored the link between balance and visual processing using visual attention tests and a force platform for measuring balance, with similar results. Our study focused on the decrease in performance on attention tasks when there is a simultaneous balance demand, as previously assessed by McIlroy et al. (1999) in adults. Both studies reached similar conclusions and their results concur: when there is greater balance challenge, attention performance decreases.

However, there exist studies inconsistent with these findings. Studies in children have produced mixed results, possibly due to the different approaches taken by the researchers. Many such studies have linked motor abilities/skills with cognitive functions, and it should be noted that these are very broad constructs. Motor abilities include a range of concepts, such as coordination, laterality, strength, and balance; cognitive functions include processes such as perception, attention, memory, and problem solving. Ac- 
cordingly, studies have failed to find relationships between balance and attention (Livesey et al., 2006; Niederer et al., 2011; Pitcher et al., 2003).

Regarding the findings of gender-mediated differences in performance on attention tests when balance is challenged, our data agree with those of several prior studies (Van Waelvelde et al., 2008) that did not find any differences between preschool boys' and girls' balance skills. The link between visual attention and balance must be considered to explain the better performance of the boys in this sample on the attention test in the BC (i.e., on an unstable platform). Livesey et al. (2006) reported gender differences in visual-spatial processing in 4-year-old children that could underlie the differences found here, in the frame of theories of limited attentional resources (Livesey and Intili, 1996). If boys have a greater ability to manage visual cues than girls, the balance of boys may be less affected by competition for attentional resources when performing two simultaneous tasks (i.e., visual attention and balance). That findings may condition the way we address balance problems in clinical approaches. Girls may need extra visual cues for their balance organization and maybe balance training programs should be personalized according to gender.

Finally, Livesey et al. (2006) noted the role of balance issues in the Diagnostic and Statistical Manual of Mental Disorders, Fifth Edition ADHD diagnostic criteria, and other results suggest a relationship between ADHD prognosis and balance skills. Other researchers, such as Ghanizadeh (2011), dispute this relationship and suggest that comorbid psychiatric disorders may underlie the balance problems in children with ADHD. Therefore, it would be worth exploring our findings in a sample of individuals with ADHD, to determine if a comprehensive assessment of motor and cognitive components is needed in these children (Williams et al., 2013). Additionally, interventions addressing motor components of balance should be considered in the future.

In children aged 4-5, there is a relationship between attention and balance abilities as assessed when participants are seated condition that becomes more significant when the attention system is stressed by adding a balance task. Greater balance skills are associated with attention performance in terms of reducing $\mathrm{OM}, \mathrm{COM}$, and RT (factors that lead to a decreased ADHD-risk score) and lead to better stimulus discrimination.

The influence of balance on attentional performance is not homogenous; it is more pronounced in accuracy- and speed-related attentional parameters (i.e., OM, COM, and RT) than in sensitivity $\left(d^{\prime}\right)$ or bias $(\beta)$ attentional parameters.

There exist gender differences in attentional performance. In the SC, girls showed better performance, but in the $\mathrm{BC}$, boys improved their performance. These relationships should be explored in more complex, broader studies to further clarify their mechanisms.

\section{CONFLICT OF INTEREST}

No potential conflict of interest relevant to this article was reported.

\section{REFERENCES}

Assaiante C, Amblard B. An ontogenetic model for the sensorimotor organization of balance control in humans. Hum Mov Sci 1995;14:13-43.

Barnard H, Rao R, Xu Y, Froehlich T, Epstein J, Lanphear BP, Yolton K. Association of the Conners' Kiddie Continuous Performance Test (K-CPT) performance and parent-report measures of behavior and executive functioning. J Atten Disord 2015 Apr 6 [Epub]. pii: 10870547 15578271.

Brown LA, Shumway-Cook A, Woollacott MH. Attentional demands and postural recovery: the effects of aging. J Gerontol A Biol Sci Med Sci 1999;54:M165-171.

Franjoine MR, Gunther JS, Taylor MJ. Pediatric balance scale: a modified version of the berg balance scale for the school-age child with mild to moderate motor impairment. Pediatr Phys Ther 2003;15:114-128.

Ghanizadeh A. Predictors of postural stability in children with ADHD. J Atten Disord 2011;15:604-610.

Hatzitaki V, Zisi V, Kollias I, Kioumourtzoglou E. Perceptual-motor contributions to static and dynamic balance control in children. J Mot Behav 2002;34:161-170.

Horak FB. Postural orientation and equilibrium: what do we need to know about neural control of balance to prevent falls? Age Ageing 2006;35 Suppl 2:ii7-ii11.

Kerr B, Condon SM, McDonald LA. Cognitive spatial processing and the regulation of posture. J Exp Psychol Hum Percept Perform 1985;11: 617-622.

Kim SM, Hyun GJ, Jung TW, Son YD, Cho IH, Kee BS, Han DH. Balance deficit and brain connectivity in children with attention-deficit/hyperactivity disorder. Psychiatry Investig 2017;14:452-457.

Lajoie Y, Teasdale N, Bard C, Fleury M. Attentional demands for static and dynamic equilibrium. Exp Brain Res 1993;97:139-144.

Livesey D, Keen J, Rouse J, White F. The relationship between measures of executive function, motor performance and externalising behaviour in 5- and 6-year-old children. Hum Mov Sci 2006;25:50-64.

Livesey DJ, Intili D. A gender difference in visual-spatial ability in 4-year- 
old children: effects on performance of a kinesthetic acuity task. J Exp Child Psychol 1996;63:436-446.

Maylor EA, Wing AM. Age differences in postural stability are increased by additional cognitive demands. J Gerontol B Psychol Sci Soc Sci 1996; 51:P143-154.

McCollum G, Leen TK. Form and exploration of mechanical stability limits in erect stance. J Mot Behav 1989;21:225-244.

McCulloch KL, Buxton E, Hackney J, Lowers S. Balance, attention, and dual-task performance during walking after brain injury: associations with falls history. J Head Trauma Rehabil 2010;25:155-163.

Mcllroy WE, Norrie RG, Brooke JD, Bishop DC, Nelson AJ, Maki BE. Temporal properties of attention sharing consequent to disturbed balance. Neuroreport 1999;10:2895-2899.

Niederer I, Kriemler S, Gut J, Hartmann T, Schindler C, Barral J, Puder JJ. Relationship of aerobic fitness and motor skills with memory and attention in preschoolers (Ballabeina): a cross-sectional and longitudinal study. BMC Pediatr 2011;11:34.

Piek JP, Dyck MJ, Nieman A, Anderson M, Hay D, Smith LM, McCoy M, Hallmayer J. The relationship between motor coordination, executive functioning and attention in school aged children. Arch Clin Neuropsychol 2004;19:1063-1076.

Piek JP, Pitcher TM, Hay DA. Motor coordination and kinaesthesis in boys with attention deficit-hyperactivity disorder. Dev Med Child Neurol 1999;41:159-165.

Pitcher TM, Piek JP, Hay DA. Fine and gross motor ability in males with ADHD. Dev Med Child Neurol 2003;45:525-535.

Reilly DS, van Donkelaar P, Saavedra S, Woollacott MH. Interaction between the development of postural control and the executive function of attention. J Mot Behav 2008;40:90-102.

Rizzoli-Córdoba A, Campos-Maldonado MC, Vélez-Andrade VH, Delgado-Ginebra I, Baqueiro-Hernández CI, Villasís-Keever MÁ, ReyesMorales H, Ojeda-Lara L6, Davis-Martínez EB, O'Shea-Cuevas G, Aceves-Villagrán D, Carrasco-Mendoza J, Villagrán-Muñoz VM, Halley-Castillo E, Sidonio-Aguayo B, Palma-Tavera JA, Muñoz-Hernán- dez O. Diagnostic evaluation of the developmental level in children identified at risk of delay through the Child Development Evaluation Test. Bol Med Hosp Infant Mex 2015;72:397-408.

Roebers CM, Kauer M. Motor and cognitive control in a normative sample of 7-year-olds. Dev Sci 2009;12:175-181.

Roebers CM, Röthlisberger M, Neuenschwander R, Cimeli P, Michel E, Jäger $\mathrm{K}$. The relation between cognitive and motor performance and their relevance for children's transition to school: a latent variable approach. Hum Mov Sci 2014;33:284-297.

Shumway-Cook A, Horak FB. Assessing the influence of sensory interaction of balance. Suggestion from the field. Phys Ther 1986;66:15481550.

Steindl R, Kunz K, Schrott-Fischer A, Scholtz AW. Effect of age and sex on maturation of sensory systems and balance control. Dev Med Child Neurol 2006;48:477-482.

Stelmach GE, Zelaznik HN, Lowe D. The influence of aging and attentional demands on recovery from postural instability. Aging (Milano) 1990;2:155-161.

Sun H, Jensen R. Body segment growth during infancy. J Biomech 1994; 27:265-275.

van der Fels IM, Te Wierike SC, Hartman E, Elferink-Gemser MT, Smith J, Visscher $\mathrm{C}$. The relationship between motor skills and cognitive skills in 4-16 year old typically developing children: a systematic review. J Sci Med Sport 2015;18:697-703.

Van Waelvelde H, Peersman W, Lenoir M, Smits Engelsman BC, Henderson SE. The movement assessment battery for children: similarities and differences between 4- and 5-year-old children from Flanders and the United States. Pediatr Phys Ther 2008;20:30-38.

Williams J, Omizzolo C, Galea MP, Vance A. Motor imagery skills of children with attention deficit hyperactivity disorder and developmental coordination disorder. Hum Mov Sci 2013;32:121-135.

Woollacott M, Shumway-Cook A. Attention and the control of posture and gait: a review of an emerging area of research. Gait Posture 2002; 16:1-14. 